\title{
Synergy between INSAT-3D infra-red and GPM microwave radiometer for precipitation studies
}

\author{
R. M. GAIROLA ${ }^{1}$, M. T. BUSHAIR ${ }^{1,2 *}$ and Raj KUMAR ${ }^{1}$ \\ ${ }^{1}$ Atmospheric and Oceanic Science Group, Earth, Ocean, Atmosphere, Planetary Sciences and applications Area, \\ Space Applications Centre, Ahmedabad, 380015, India. \\ ${ }^{2}$ National Centre for Medium Range Weather Forecasting (NCMRWF), Ministry of Earth Sciences, Noida, 201309, \\ India. \\ *Corresponding author; email: bushairmt@gmail.com
}

Received: September 15, 2018; accepted: October 10, 2019

\section{RESUMEN}

El algoritmo multiespectral de precipitación (IMSRA, por sus siglas en inglés) del Sistema Nacional de Satélites de la India (INSAT) provee operativamente estimaciones de precipitación sobre el territorio continental y las regiones oceánicas de la India utilizando mediciones proporcionadas por el satélite Kalpana a partir de 2008 y el satélite INSAT-3D a partir de 2014. En este estudio se pretende estimar la precipitación sobre la región del monzón de la India mediante el uso sinérgico de estimaciones geostacionarias derivadas de INSAT-3D e IMSRA, así como datos de precipitación del generador de imágenes por microondas del proyecto global para la medición de la precipitación (GPM-GPI, por sus siglas en inglés), utilizando para ello un método apropiado de análisis objetivo. Los criterios objetivos de un método de corrección sucesiva se benefician de las altas resoluciones temporales y espaciales del satélite geoestacionario, así como de estimaciones infrecuentes pero más exactas de precipitación basadas en microondas, particularmente en condiciones de lluvia intensa. El método se aplica a varios casos de estudio para la temporada 2015 de monzón del suroeste tanto a escala instantánea como diaria. Se realiza una comparación con datos de campo y productos globales independientes de precipitación. Las estimaciones combinadas muestran una mejoría notable con relación a las estimaciones basadas en el infrarrojo sobre varias partes de las regiones continental y oceánica de la India en una escala diaria. En general, los resultados muestran que el radiómetro GMI en una órbita baja e inclinada (como la de las misiones Megha-Tropiques y TRMM), podría ser de mayor utilidad si es utilizado de manera sinérgica con el INSAT-3D. Tiene el potencial de predecir lluvias tropicales con mayor precisión y casi en tiempo real, sobre todo en la región del monzón de la India, por lo cual es una importante fuente de información para pronóstico de inundaciones, manejo de recursos agrícolas e hídricos, predicción numérica del tiempo y muchas otras aplicaciones en las ciencias hidrometeorológicas.

\section{ABSTRACT}

The Indian National Satellite System (INSAT) based Multispectral Rainfall Algorithm (IMSRA) operationally provides precipitation estimates using measurements provided by the Kalpana satellite from 2008 onwards and the INSAT-3D from 2014 onwards over Indian land and oceanic regions for dissemination to the users. Here, an attempt is made to estimate rainfall over the Indian monsoon region by the synergistic use of geostationary INSAT-3D IMSRA derived rainfall estimates and rain data from the Global Precipitation Measurement (GPM) Microwave Imager (GMI) using a suitable objective analysis method. The objective criteria of a successive correction method benefit from high spatial and temporal resolutions of the geostationary satellite and infrequent but more accurate microwave-based rainfall estimates, particularly during heavy rain conditions. The method is applied to various case studies for the southwest monsoon season of 2015 at both instantaneous and daily scale. A comparison is made with ground data and also with independent global concurrent rainfall 
products. The merged rainfall estimates shows noticeable improvement over the Infrared (IR)-based rainfall estimates over various parts of the Indian land and oceanic regions on a daily scale. Overall, results reveal that the GMI type radiometer in low inclination orbit like the Megha-Tropiques and Tropical Rainfall Measurement Mission (TRMM) could be more useful for synergistic use with INSAT-3D. It has the potential to predict more accurately near real-time tropical rainfall, particularly over the Indian monsoon region, which makes it a valuable source of information for flood forecasting, agriculture and water resource management, numerical weather prediction, and numerous other applications in the hydro-meteorological sciences.

Keywords: Precipitation, objective analysis, global precipitation mission, INSAT-3D

\section{Introduction}

Accurate rainfall estimation over India has vital importance in agricultural production, which has a large impact in social and economic life. The best sources for accurate rainfall estimation are rain gauges and weather radars, but the heterogeneous distributions over land and oceanic regions limit their use for meteorological applications. Alternatively, satellite-based rainfall estimations provide continuous spatial and temporal distributions of rainfall, which enable more accurate flood forecasting, agriculture and water resource management, numerical weather prediction, moisture budget calculations and many other applications in hydro-meteorological sciences.

Rainfall estimation techniques using meteorological satellites have improved quite rapidly in recent decades. As geostationary satellites provide frequent updates of weather systems at high spatial resolution, they are supposed to be a viable source of information for Indian monsoon monitoring. Following the launch in 2002 of the first Indian dedicated meteorological satellite, Kalpana-1, by the Indian Space Research Organization (ISRO), it is now possible to monitor the onset, progress and performance of the Indian monsoon consistently for various applications (Kaila et al., 2002). The advanced meteorological satellite of the Indian National Satellite System (INSAT-3D) is more useful for weather studies, since it has higher spatial and temporal resolution and increased number of channels. An overview of satellite-based rainfall estimation methods is given by Levizzani et al. (2002). Also, some satellite-based rainfall estimation techniques are developed by integrating infrared (IR) and passive microwave techniques, which are applied to the monitoring of various weather parameters and rainfall events (Gairola and Krishnamurti, 1992; Gairola et al., 2003; Prakash et al., 2010).
The first technique for rainfall estimation is developed by deriving a simple relationship with visible (VIS) and IR brightness temperature (BT), which has the advantage of being easy to apply but also shows a relatively low degree of accuracy (Levizzani et al., 2002). The main drawback of IR channels is that they only provide information about cloud top. Therefore, the major problem of estimating rainfall from these measurements is the difficulty to distinguish between precipitating and non-precipitating clouds. In general, methods based on cloud-top temperature tend to overestimate rainfall in dry environments and underestimate it in more humid atmospheres. A complete overview of the early work and physical premises of VIS and thermal IR (10.5-12.5 $\mu \mathrm{m})$ techniques is provided by Barrett and Martin (1981) and Kidder and Vonder Haar (1995). This technique is mostly used in climatological applications over long time scales. But there are some sources of errors due to the presence of high-level cirrus and other non-precipitating clouds often considered as precipitating with this simple relationship. After the initiation of passive microwave (MW) measurements, several existing VIS/IR techniques were re-examined and some of the well-known problems such as inferring precipitation only from cloud top information were addressed. At passive MW frequencies, the attenuation of upwelling radiation is mainly due to oxygen and water vapor. Thus, MW techniques are physically more appropriate than those based on VIS/IR radiation. Depending on the frequency of the upwelling radiation, the size and type of precipitation particles can be detected (Liu and Curry, 1993). Some commonly used passive MW precipitation estimation techniques use scattering index (SI) (Ferraro et al., 1994) and polarization corrected temperature (PCT) (Spencer et al., 1989) for precipitation estimation over land and ocean. Moreover, the combined use of SI and PCT can pro- 
vide more accurate precipitation estimates than the single SI or PCT based method (Mahesh et al., 2011). An overview of passive MW rainfall estimation methods is given by Wilheit et al. (1994) and Gairola et al. (2003). Various geophysical parameters like rain rate, cloud liquid water, integrated water vapor, ocean surface wind speed, etc., can also be estimated using microwave measurements. The biggest limitation of MW sensors over VIS/IR sensors is their poor spatial and temporal resolution. Hence, passive MW techniques perform mainly for instantaneous applications over land and oceans, while combined IR and MW techniques show improvement in a wide variety of applications. Merging of MW, VIS and IR imagery data provides further scope for the improvement of instantaneous rainfall retrievals. The Adjusted Geostationary Operational Environmental Satellites Precipitation Index (GOES-AGPI) method proposed by Adler et al. (1994) corrects the GOES Precipitation Index (GPI) monthly rainfall estimates (Arkin and Meisner, 1987) using an adjustment factor based on MW and IR data. Xu et al. (1999) developed the MW and IR data-based new Universally Adjusted GPI (UAGPI) method, which provides stable estimates of monthly rainfall at different spatial scales. Gairola et al. (2015a) demonstrated a combined satellite-IR and rain gauge-based rainfall algorithm and the results were highly encouraging.

Global satellite-based rainfall products are being generated from various sources like low earth orbiting microwave sensors, IR sensors in geostationary platforms, and combined microwave and IR observations from various satellite missions using a variety of merging techniques (e.g., Sorooshian et al., 2000; Kuligowski, 2002; Kidd et al., 2003; Turk and Miller, 2005; Huffman et al., 2007; Kubota et al. 2007; Joyce et al., 2011; Mitra et al., 2003, 2009, 2013). All the available products differ in measurement accuracy, sampling frequency, and merging methodology. MW sensors are the most suitable instruments for estimating precipitation, since the radiative signatures are more directly linked to precipitating particles, whereas IR sensors on geostationary platforms only provide precipitation estimates from cloud top radiances at high temporal resolutions (up to 15-min intervals on some platforms). The microwave-calibrated infrared measurements of brightness temperature can provide essential information for the estimation of rainfall fields, decreasing the traditional dependency on the point measurements.

In the present study, the Global Precipitation Mission (GPM) Microwave Imager (GMI) estimated rainfall, based on the Goddard profiling algorithm (GPROF) (Kummerow et al., 2015), is used for merging with INSAT-3D IR based rainfall. The IMSRA algorithm (Gairola et al., 2015b) has been applied routinely to INSAT-3D data for estimating rainfall over Indian land and oceanic regions. For each INSAT-3D image, collocated passes of GPM are used for objective analysis. This experiment was done for all available images of INSAT-3D for the complete period of the 2015 southwest (SW) monsoon. GMI-based rainfall data is considered as the more accurate rainfall product for merging with IR-based INSAT-3D rainfall data. Finally, both the ground based and the concurrent independent satellite based products are utilized for validation. The dominant component for the validation of merged IMSRA (M-IMSRA) rain products are ground data for a period longer than 122 days (June 1 to September 30, 2016) of rain gauge data from the Indian Meteorology Department (IMD). This represents the complete SW monsoon domain, having all possible dynamic ranges of rainfall amounts. The M-IMSRA data is also validated with independent data form the Tropical Rainfall Measuring Mission (TRMM) Multi-satellite Precipitation Analysis (TMPA-3B42) (Huffman et al., 2003; 2007), and with the concurrent Integrated Multi-satellitE Retrievals for GPM (IMERG) product (Huffman et al., 2015).

\section{Data sources}

\subsection{INSAT-3D data}

The INSAT-3D satellite is an advanced weather satellite launched by the Ariane-5 ECA and operating since July 26, 2013. This geostationary satellite carries four payloads: a six channel multi-spectral imager, a 19 channel sounder, a data relay transponder (DRT), and search and rescue transponders. The multi-spectral imager operates in six wavelength bands, namely visible, short wave IR (SWIR), mid wave IR (MWIR), water vapor (WV), thermal infrared-1 (TIR1) and thermal infrared -2 (TIR2). The details of wavelengths and spatial resolutions are presented in Table I. The operational product used 
Table I. INSAT-3D imager band names, wavelengths and spatial resolution.

\begin{tabular}{lcc}
\hline Band name & $\begin{array}{c}\text { Wavelength } \\
(\mu \mathrm{m})\end{array}$ & $\begin{array}{c}\text { Spatial resolution } \\
(\mathrm{km})\end{array}$ \\
\hline Visible (VIS) & $0.55-0.75$ & 1 \\
Short wave infrared (SWIR) & $1.55-1.70$ & 1 \\
Middle wave infrared (MWIR) & $3.80-4.0$ & 4 \\
Water vapor (WV) & $6.50-7.10$ & 8 \\
Thermal infrared-1 (TIR1) & $10.3-11.3$ & 4 \\
Thermal infrared-2 (TIR2) & $11.50-12.50$ & 4 \\
\hline
\end{tabular}

for this study is the INSAT Multi-Spectral Rainfall Algorithm (IMSRA), which takes advantage of the accuracy of MW-based estimates and relatively low sampling errors of IR-based estimates (Prakash et al., 2009; Gairola et al., 2010). The development of IMSRA includes two major steps: the classification of rain-bearing clouds with a cloud classification scheme (Roca et al., 2002) utilizing Kalpana-1 IR and WV BTs. This scheme is able to delineate the non-raining clouds based on the threshold BTs in both IR and WV channels. Afterwards, a proper spatial and temporal collocation of Kalpana-1 IR BTs with TRMM-precipitation radar (PR) surface rain rate is generated to establish a regression relation between them. The rainfall products from this method were tested for different weather conditions in different temporal and spatial scales using standard rainfall products and satisfactory error statistics were reported (Prakash et al., 2009; 2010; Mahesh et al., 2014a, b; Gairola et al., 2014; Bushair et al., 2016, 2019). This algorithm was developed for small-scale precipitation estimation over the Indian region and the rainfall dataset may be downloaded from https:// www.mosdac.gov.in.

\subsection{GPM-GMI rainfall products}

The GPM mission is exclusively intended for advanced precipitation measurements from a low-Earth orbit platform using microwave sensors. After the success of TRMM, the National Aeronautics and Space Administration (NASA) and Japan Aerospace Exploration Agency (JAXA) successfully launched the GPM core satellite on February 28, 2014. The satellite carries the first space borne dual-frequency precipitation radar (DPR) operating at $\mathrm{Ku}(13.6 \mathrm{GHz})$ and $\mathrm{Ka}(35.5 \mathrm{GHz})$ and a conical-scanning multi- channel (10-183 GHz) microwave imager (GMI). This sensor package is an advanced form of TRMM instruments (Kummerow et al., 1998), and has the capability to estimate from heavy rain to light rain over tropical and subtropical land and oceans. The $\mathrm{Ku}$ band precipitation radar (KuPR) and $\mathrm{Ka}$ band precipitation radar (KaPR) provide co-aligned 5-km resolution footprints on Earth's surface, with cross track swath widths of $245 \mathrm{~km}$ and $120 \mathrm{~km}$, respectively. Both radars have nominal vertical range resolution of $250 \mathrm{~m}$, sampled at every $125 \mathrm{~m}$ (Hou et al., 2014). Heavy, moderate, and light precipitation can be detected with the help of different channels (10 to $183 \mathrm{GHz}$ ) present in the GMI sensor. For this study, GPM-GMI retrieved rainfall is used (Kummerow et al., 2015; Brown et al., 2016), which is downloaded from the Precipitation Processing System (PPS).

\subsection{Integrated Multi-satellitE retrievals for GPM (IMERG)}

IMERG is an integrated algorithm that provides a multi-satellite precipitation product in every half hour at $0.10^{\circ} \times 0.10^{\circ}$ resolutions based on the GPM satellite. This algorithm inter-calibrates, merges and interpolates all available satellite microwave precipitation estimates (Table II) together with microwave-calibrated IR satellite estimates, precipitation gauge analyses, and potentially other precipitation estimators at fine time and space over the entire globe (Huffman et al., 2015; Kirschbaum et al., 2016). IMERG also includes temporal interpolation and "morphing" of MW rain rate estimates using IR data. Recently, Prakash et al. (2015) assessed the performance of the GPM-based IMERG rainfall product against IMD rain gauge data over the Indian territory. A notable improvement over TMPA-3B42 
for detecting heavy rainfall frequency across India at daily time scale during SW monsoon season was reported. In this study, the IMERG product is used for qualitative comparison to assess the accuracies of the proposed regional algorithm for merging with INSAT-3D. IMERG data is downloaded from the Precipitation Processing System (PPS) webpage at ftp://arthurhou.pps.eosdis.nasa.gov/.

\subsection{TMPA-3B42 data}

TRMM was a joint US-Japan Satellite Mission to monitor tropical and subtropical precipitation and to estimate its associated latent heating. It was launched in late November 1997 to a near circular orbit approximately at $350 \mathrm{~km}$ altitude (raised to $403 \mathrm{~km}$ since 2001 ) at a $35^{\circ}$ inclination from the equatorial plane. After 17 years of productive service in space, the instruments of TRMM switched off on 08 April, 2015. The complete description of the sensor package of TRMM is given by Kummerow et al. (1998). The operational TRMM data set used in the present study is called 3B42, which is a merged product from Geostationary IR and Microwave data (Huffman et al., 2003, 2007). The 3B42 estimates are produced in four stages: (1) calibrating and combining the microwave estimates precipitation, (2) creating the infrared precipitation estimates using calibrated microwave precipitation, (3) combining the microwave and IR estimates, and (4) rescaling to monthly data. Even though the satellite is switched off, the TMPA-3B42 product is still generated (likely to be continued in 2018) from all available sensors. This product has been obtained from the TRMM Online Visualization and Archive System (TOVAS) in $0.25^{\circ}$ x $0.25^{\circ}$ grid for inter-comparison purposes. The TMPA-3B42 product is also used for validation purposes.

\subsection{IMD gridded gauge based rainfall data}

Surface rain gauge (SRG) based daily gridded rainfall data over the Indian land is available since January 1901 at a spatial resolution of $0.25^{\circ} \times 0.25^{\circ}$. This data set is prepared by the India Meteorological Department (IMD) from daily measurements from about 7000 SRG stations well-spread across the country after performing the necessary quality control test (Pai et al., 2014), which involves verifying the location of the gauge station, eliminating missing data and coding errors, performing extreme value checks, etc. These data are interpolated using the Shepard interpolation method into a regular grid. The distribution of gauges over India is satisfactory in terms of number and regional distribution, except some small regions of Jammu and Kashmir, as well as the extreme northwest parts of India (Pai et al., 2014).

\section{Methodology}

Satellites with suitable IR and MW sensor channels provide very useful information about rainfall. These datasets could be further improved using ground station values by blending satellite data with station(s) data. The common procedure adopted in blending is performed using a modified inverse distance weighting (IDW) approach that borrows some concepts from the kriging, particularly simple and

Table II. Members of the GPM constellation.

Advanced Microwave Scanning Radiometer (AMSR)-2/Global Change Observation Mission for Water (GCOMW)-1

Special Sensor Microwave Imager/Sounder (SSMIS)/Defense Meteorological Satellite Program (DMSP)

Microwave Analysis and Detection of Rain and Atmospheric Structures (MADRAS)/Megha Tropiques

Sounder for Probing Vertical Profiles of Humidity (SAPHIR)/Megha Tropiques

Microwave Humidity Sounding (MHS)/National Oceanic and Atmospheric Administration (NOAA)-19

MHS/Meteorological operational satellite (MetOP) series

Advanced Technology Microwave Sounder (ATMS)/Suomi National Polar-orbiting Partnership (SNPP)

ATMS/Joint Polar Satellite System (JPSS) and Defense Weather Satellite System (DWSS) 
ordinary kriging. The basic process uses two datasets: (1) a point dataset with values at discrete points in space (e.g., rain gauges) which requires fairly good information to ensure reasonable representativeness and (2) a grid dataset with values varying continuously over space (e.g., a satellite-based rainfall estimate pixel, grid or a climatic average). With this concept, INSAT-3D IMSRA derived rainfall and GMI derived rainfall $\left(>1 \mathrm{~mm} \mathrm{hr}^{-1}\right)$ are merged using the successive correction method (Cressman, 1959; Thiebaux and Pedder, 1987), which is one of the most popular and simple techniques. The basic need for augmentation of INSAT-3D-based IMSRA rainfall data is that it underestimates high rain events. At the same time, multichannel microwave measurements from GMI portray heavy rainfall quite well. Less than $1 \mathrm{~mm} \mathrm{hr}^{-1}$ of rainfall may invariably be seen in GMI, as observed in the sub-satellite tracks (Figs. $1 \mathrm{~b}$ and $2 \mathrm{~b}$ ) where it seems like noise or artifacts that could influence the final products. Thus, a threshold of $1 \mathrm{~mm} \mathrm{hr}^{-1}$ is reasonably chosen for removing the noise while combining the two measurements (a) IMSRA Rain $(\mathrm{mm} / \mathrm{h})$

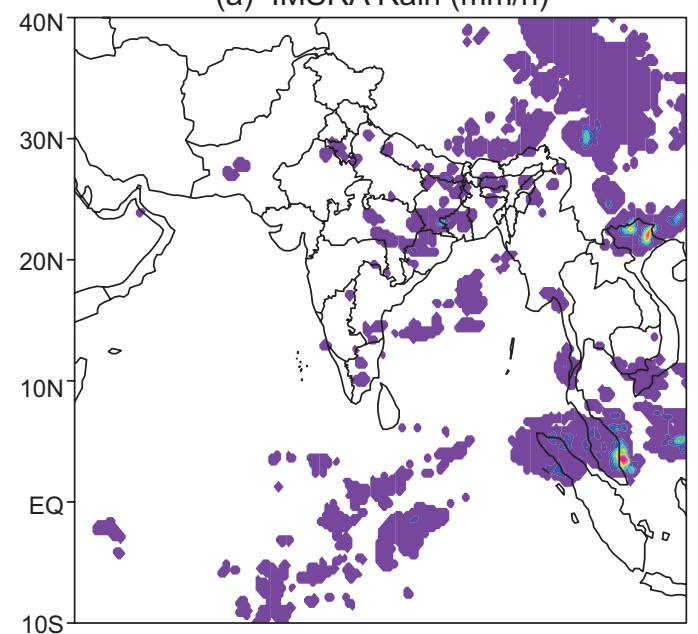

(c) M-IMSRA Rain $(\mathrm{mm} / \mathrm{h})$

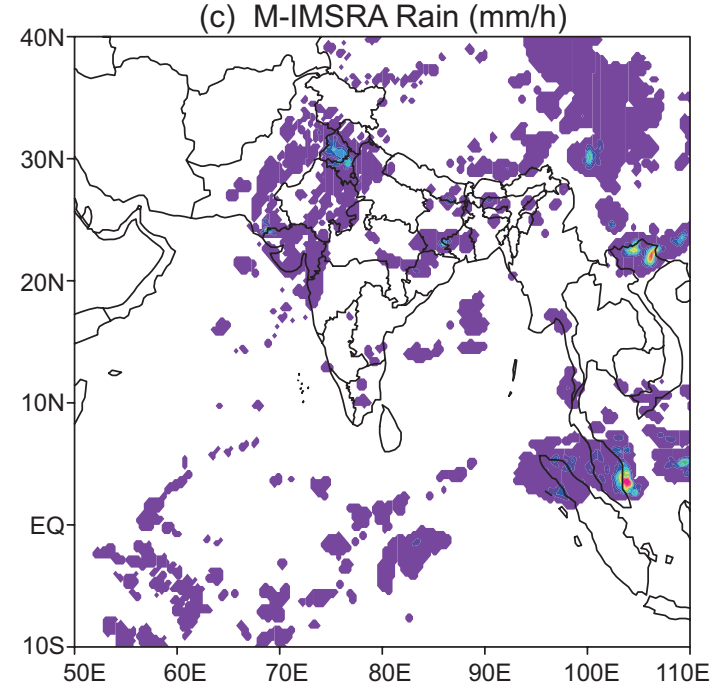

(b) GPM-GMI Rain ( $\mathrm{mm} / \mathrm{h})$

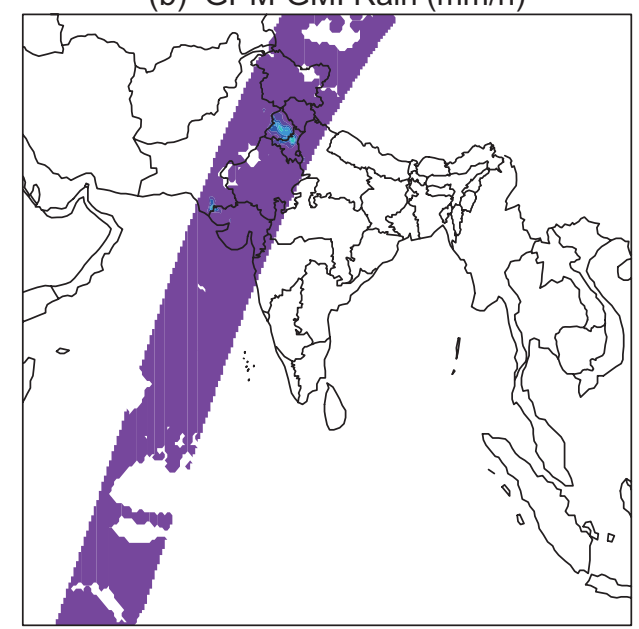

(d) IMERG Rain $(\mathrm{mm} / \mathrm{h})$

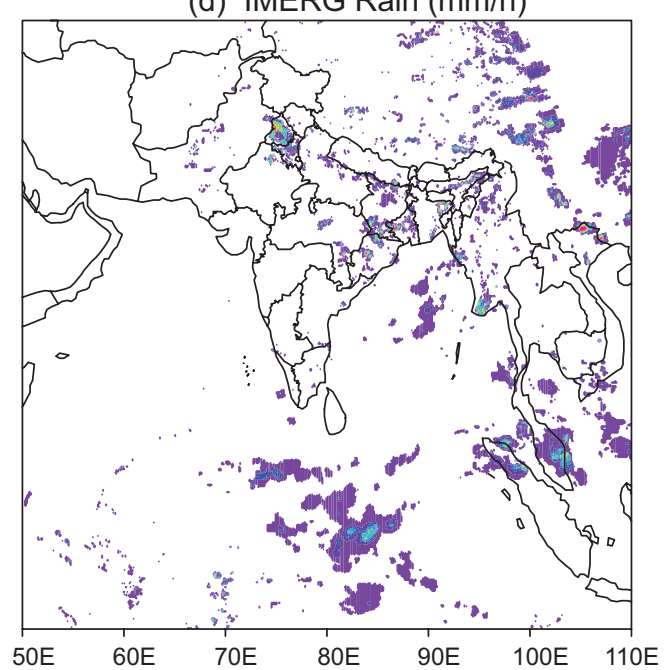

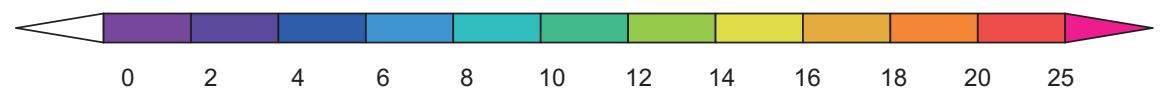

Fig. 1. Rainfall estimation for July 3, 2015 at 1400 GMT from (a) IMSRA, (b) GPM-GMI, (c) M-IMSRA and (d) IMERG. 
(a) IMSRA Rain $(\mathrm{mm} / \mathrm{h})$

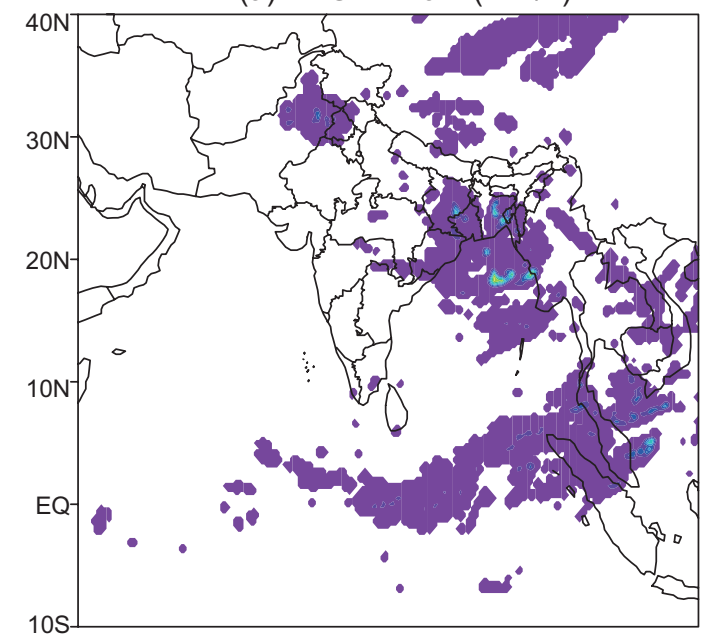

(c) M-IMSRA Rain $(\mathrm{mm} / \mathrm{h})$
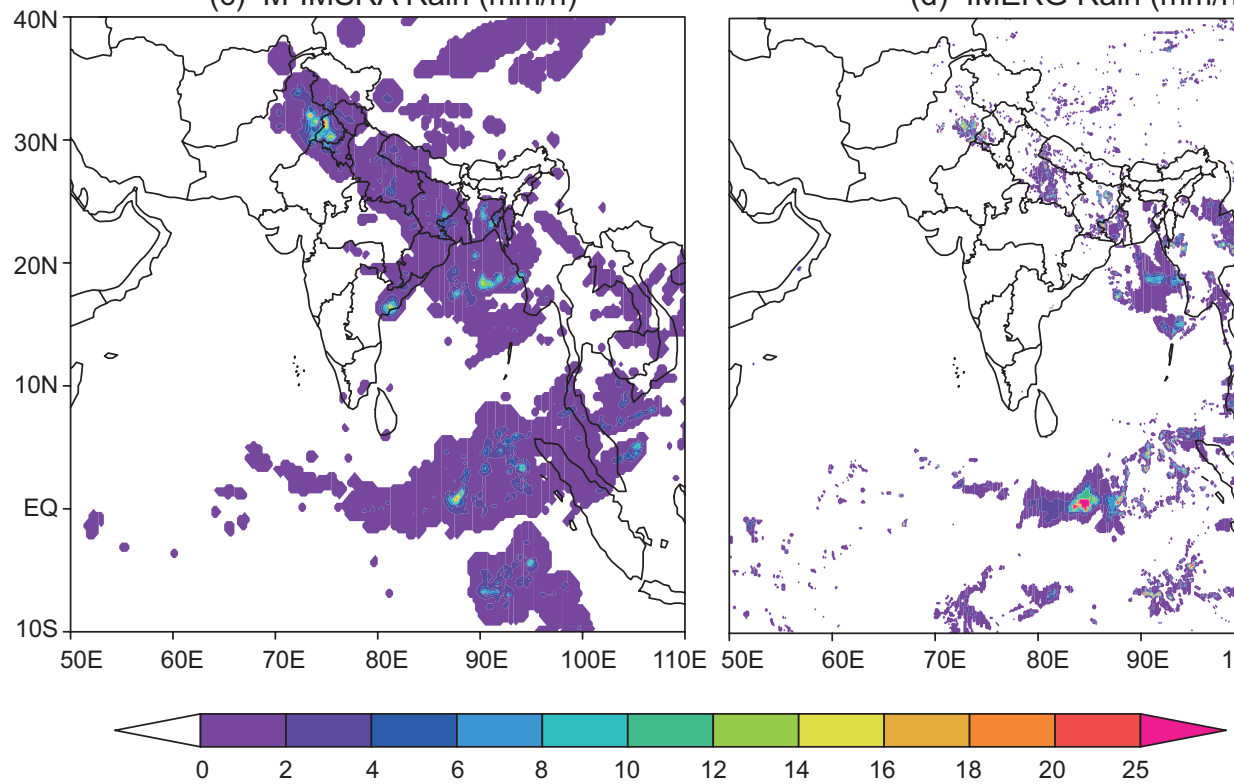

Fig. 2. Rainfall estimated on 06 July, 2015 at 2300 GMT from (a) IMSRA, (b) GPM-GMI, (c) M-IMSRA and (d) IMERG. (b) GPM-GMI Rain ( $\mathrm{mm} / \mathrm{h})$

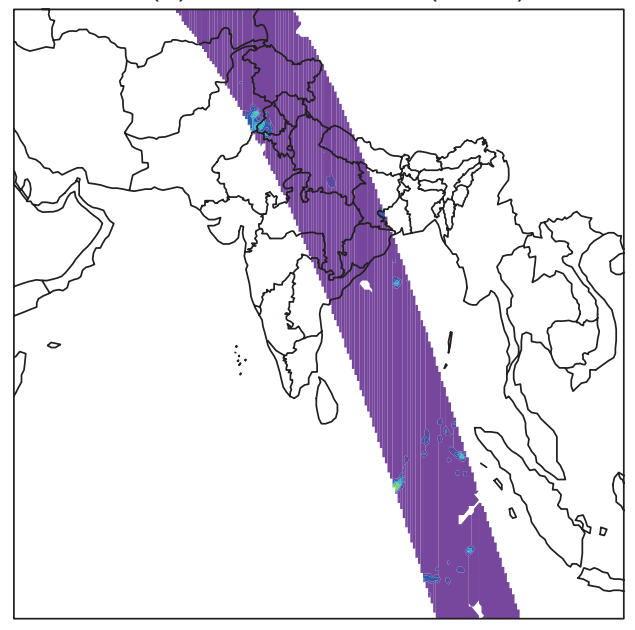

(d) IMERG Rain $(\mathrm{mm} / \mathrm{h})$

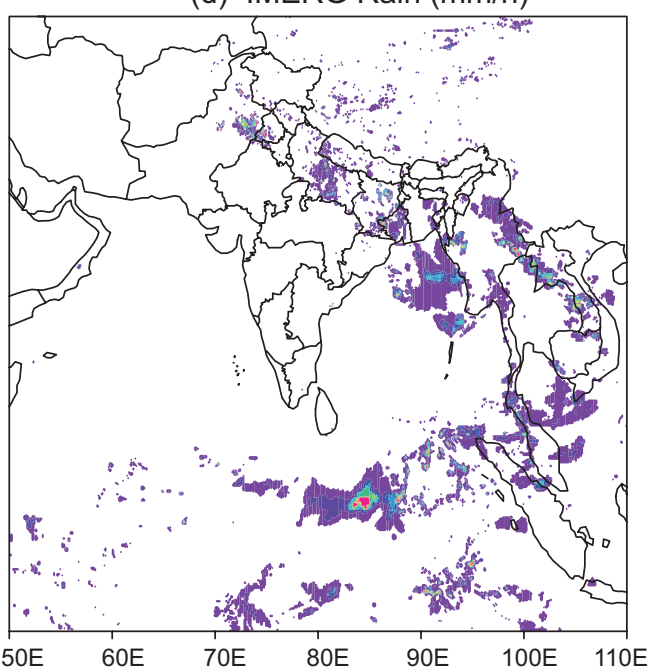


$C=\sum\left(W\left(P_{o}-P_{p}\right)\right) / N$

where $P_{\mathrm{o}}$ is rainfall at the observation point, $P_{\mathrm{p}}$ is the interpolated grid point data at the observation point, $N$ is the number of observations, and the $W$ is the weight given by

$$
\begin{aligned}
& W=\left(R^{2}-d^{2}\right) /\left(R^{2}+d^{2}\right) \text { for } d^{2} \leq R^{2} \\
& W=0 \text { for } d^{2}>R^{2}
\end{aligned}
$$

where $R$ is the radius of influence of rainfall and $d$ is the distance to the nearest reliable data point from the grid. The values of $R$ used in the successive correction method start from $10 \mathrm{~km}$ up to $50 \mathrm{~km}$, at the interval of $10 \mathrm{~km}$.

A maximum of 48 images every $30 \mathrm{~min}$ are available per day from INSAT-3D, in which IMSRA rainfall is used as background field. Here, if a GMI pass is available over its scanning region within $10 \mathrm{~min}$ of each INSAT-3D image scan time, the GMI derived rainfall is considered as the reliable data and it is merged with INSAT-3D rainfall to a spatial resolution of $\sim 10 \mathrm{~km}$ using the successive correction method. This time interval is chosen as optimal because a polar orbiting satellite (like GPM) takes approximately $10 \mathrm{~min}$ to cover the common area of study of a typical geostationary tropical observation.

The skill of IMSRA and M-IMSRA are evaluated using different verification scores. The four count (a, b, c, d) events in the $2 \times 2$ contingency table, which contains the number of hits, false alarms, misses, and correct rejections at different thresholds, are used to assess the performance of the algorithms (Mason, 2003). The bias score (BS), hit rate (HR), equitable threat score (ETS) and extreme dependence score (EDS) are computed based on the contingency table for different thresholds. A brief description of these statistical scores is given by Wilks (1995) and Ashok et al. (2002). The BS compares the total number of times an event is forecasted/estimated with the total number of times an event is observed:

$B S=\frac{(a+b)}{(a+c)}$

For an unbiased estimation, $B S=1$, whereas $B S>1$ corresponds to an overestimation and $\mathrm{BS}<1$ to an underestimation. The hit rate is the ratio of correct estimation to the total observed events:
$H R=\frac{a}{(a+c)}$

The value of HR ranges from 0 to 1 , and the more accurate the estimate, the higher the value. The equitable threat score (ETS) measures the ability to estimate/predict the precipitation above a given threshold and its value ranges from $-1 / 3$ to 1 . For a perfect estimation/forecast the value of ETS should be 1 ; if it goes below 0 , the estimation/forecast can be called as unskilled:

$E T S=\frac{(a-E)}{(a+b+c-E)}$

where $E=\frac{(a+b)(a+c)}{(a+b+c+d)}$

The ETS has the disadvantage of tending to 0 for extreme rare events. This creates the misleading impression that rare events cannot be skillfully estimated/forecasted. The extreme dependency score (EDS) is proposed as a more informative alternative for the assessment of such extreme rare events irrespective of the precipitation amount (Stephenson et al., 2008). For a perfect prediction/estimation EDS will be 1:

$E D S=2\left[\frac{\log \left(\frac{a+c)}{(a+b+c+d)}\right)}{\log \left(\frac{a}{(a+b+c+d)}\right)}\right]$

\section{Results and discussion}

Even though there is significant rainfall magnitude variation across land, India receives an annual average rainfall of $105 \mathrm{~cm}$ for the entire country, of which about $80 \%$ is contributed by the SW monsoon (Selvaraju, 2003). The successive correction method is applied to the INSAT-3D derived IMSRA half hourly rainfall for the 2015 SW monsoon season (June 1 to September 30, 2015) and M-IMSRA is generated. The results of some case studies are presented here for brevity. One case study corresponding to July 3, 2015 at 1400 GMT is presented in Figure 1. The GPM pass along the Indian region is selected during this time (within $15 \mathrm{~min}$ ) and the successive correction method is applied. Ideally, how quickly precipitation features are likely to change, depends on the de-correlation length of the rainfall process in time and spatial domain. Thus, the temporal separation has been chosen well within the time and spatial window of both INSAT-3D and GMI observations, 
which have been followed for synergy and blending in the present study.

The rainfall pattern ranging from 2-6 $\mathrm{mm}$ around $30^{\circ} \mathrm{N}$ and $77^{\circ} \mathrm{E}$ is not registered by the IMSRA product (Fig. 1a), but the GMI rainfall retrieved from the MW sensor (Fig. 1b) has clearly registered that specific high region with orography-induced rainfall around Himachal Pradesh in north of India. The light rainfall around $25^{\circ} \mathrm{N}$ and $69^{\circ} \mathrm{E}$ is also missing in the IMSRA image. After applying the successive correction method, all the MW detected rainfalls are merged with IR detected rainfall, which can be seen in the resulting product (Fig. 1c). The merged product is further compared qualitatively with the GPM-based IMERG product (Fig. 1d) for the same time. Rainfall detected around Delhi and Punjab $\left(28^{\circ}-32^{\circ} \mathrm{N}, 74^{\circ}-78^{\circ} \mathrm{E}\right)$ is registered well in the IMERG product also. Rainfall patterns found around Malaysia, Philippines, West Bengal and some regions of China are comparable in both IMERG and merged products. Another example corresponds to July 6, 2015 at 2300 GMT, which is shown in Figure 2a, b, for INSAT derived IMSRA and GMI derived rain products, respectively.

Figure $2 \mathrm{~d}$ shows high precipitation in IMERG and in the merged product (Fig. 2c) around the border between Punjab and Pakistan $\left(30^{\circ}-33^{\circ} \mathrm{N}, 74^{\circ}-76^{\circ} \mathrm{E}\right)$. All other patterns in the IMERG images are also comparable with the merged product. These case studies show the advantage of physically-based MW measurements, which can be used for successive correction of the IR-based rainfall product. The quantitative comparison of M-IMSRA with IMERG is also carried out for assessment and validation. Instantaneous images of IMSRA are compared with the concurrent IMERG rainfall for the period July $1-15,2015$, when the SW monsoon is normally active and different error statistics were calculated. The correlation coefficient between M-IMSRA and IMERG shows a notable improvement from 0.4 to 0.9 , while the correlation coefficient between IMSRA and IMERG improves from 0.3 to 0.7 as shown in Figure 3. Similarly, there is a significant improvement in root mean square deviations (RMSD) when M-IMSRA and IMSRA are compared with IMERG rain (Fig. 4).

Different verification scores of IMSRA and M-IMSRA for different thresholds are represented in Figure 5, considering IMERG rainfall as reliable information. The bias score of IMSRA and M-IMSRA does not show significant differences up to $20 \mathrm{~mm} \mathrm{hr}^{-1}$, beyond which the improvement in M-IMSRA can be seen. The BS of both products is very close to 1 up to $15 \mathrm{~mm} \mathrm{hr}^{-1}$, from which the high estimation skill of the algorithms over those thresholds may be inferred. The HR of M-IMSRA is higher than IMSRA as expected over all thresholds, which reveals the accuracy of the product for detecting rain events. The ETS of M-IMSRA is also high in all thresholds but the score gradually decreases with increasing thresholds. Over high thresholds, rain events will be less as compared to other thresholds, which may lead to low ETS values, as discussed earlier. Therefore the EDS, which is designed for extreme rare events, is found to be a more appropriate and informative

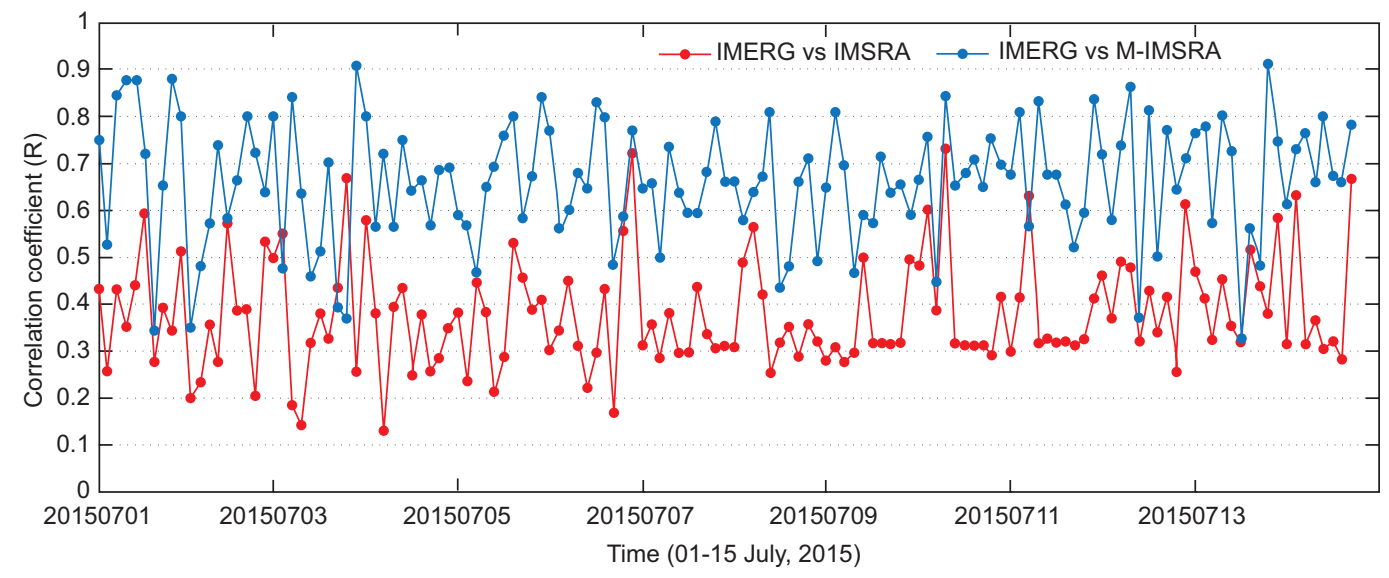

Fig. 3. Correlation coefficient of IMSRA and M-IMSRA with IMERG rainfall at instantaneous scale for the period July 1-15, 2015. 


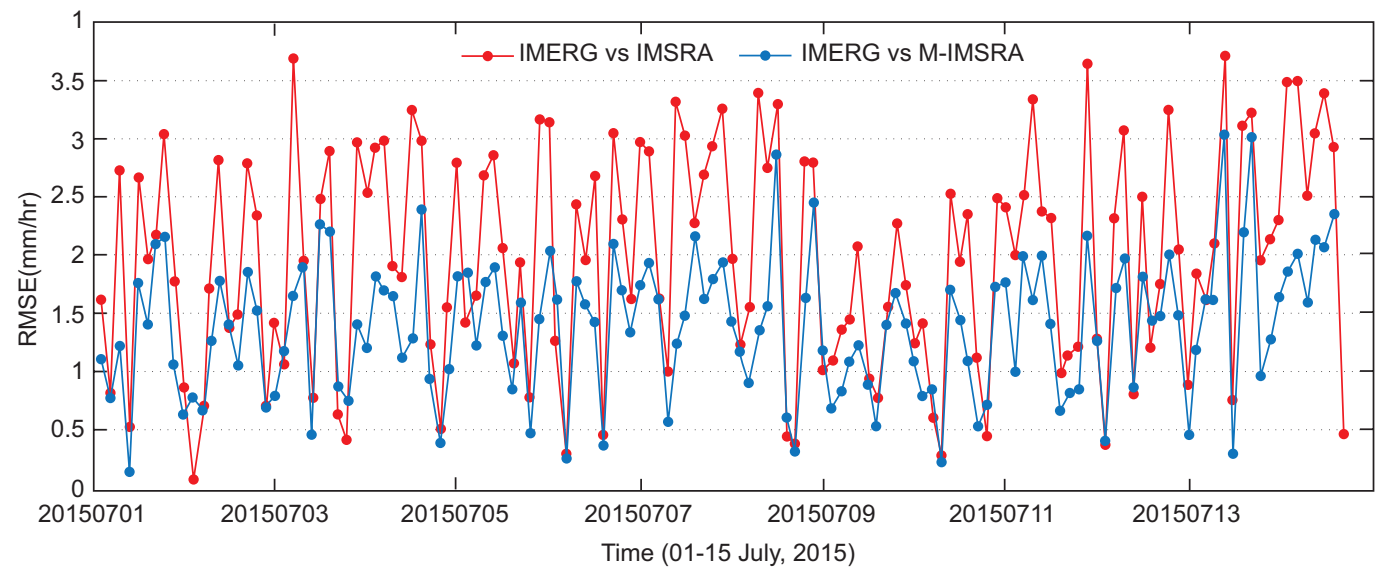

Fig. 4. Root mean square deviation of IMSRA and M-IMSRA with IMERG rainfall at instantaneous scale for the period July 1-15, 2015.

(a) Bias score

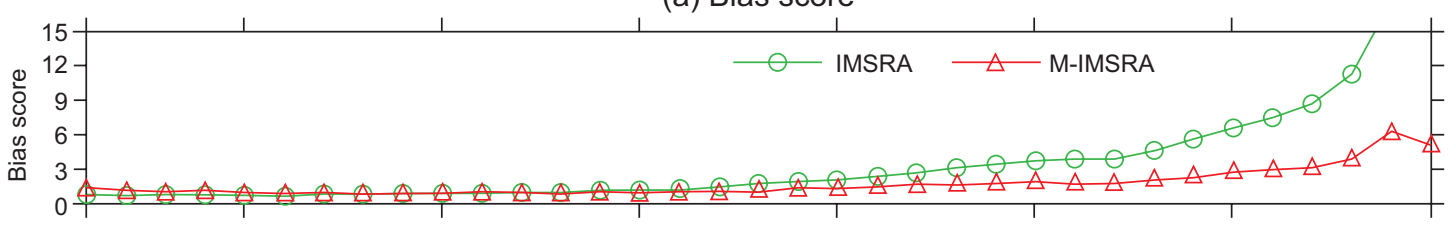

(c) Hit rate

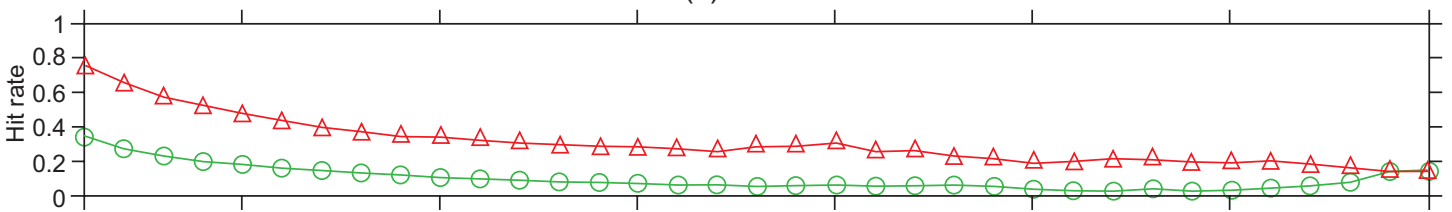

(b) ETS

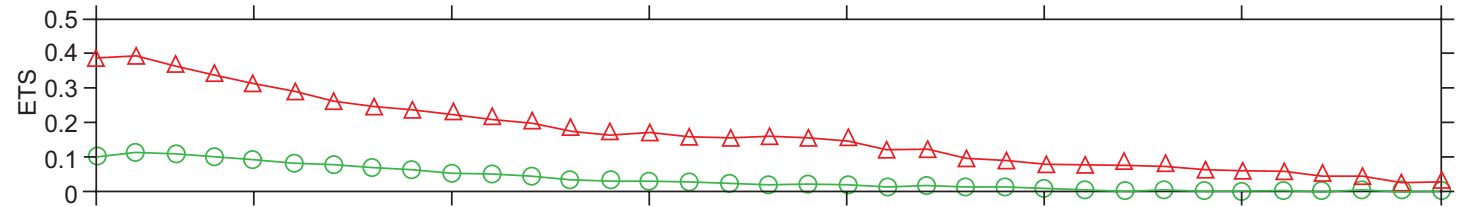

(b) EDS

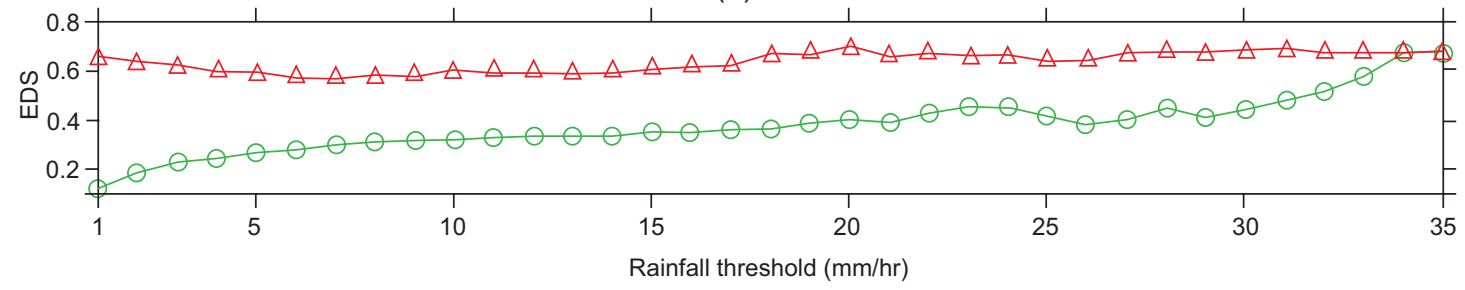

Fig. 5. (a) Bias score, (b) hit rate, (c) equitable threat score and (d) extreme dependency score from IMSRA and M-IMSRA for the period July 1-15, 2015.

verification skill as high rain events are decreasing over high thresholds. The notable point is that, over all thresholds, M-IMSRA shows higher EDS values compared to IMSRA. Hence, all verification skills clearly show the better accuracy of M-IMSRA over IMSRA over all rainfall thresholds considered. 
Further, images augmented with the GMI rain rate are used along with routine INSAT-3D images to produce the daily rainfall product. At a particular location during a day, MW-estimated rainfall from a single pass corrects only one image of INSAT-3D out of 48. These daily rainfall products are compared qualitatively and quantitatively with the TMPA-3B42 v. 7 product. For qualitative comparison, one case study corresponding to July 15, 2015 is presented (Fig. 6). All the available passes of GPM on that specific day are shown in Fig. 6a. Rainfall retrieved from each pass is merged with collocated observations of INSAT-3D images and the average daily rainfall rate $\left(\mathrm{mm} \mathrm{hr}^{-1}\right)$ is estimated (Fig. 6b). For qualitative comparison, the difference between merged IMSRA and M-IMSRA alone is represented in Fig. 6c, where it is clear that even though GMI rainfall corrects few images of INSAT-3D in a day, the improvements concerning rainfall in the daily averaged product is observed.

Daily rainfall $\left(\mathrm{mm} \mathrm{day}^{-1}\right)$ from M-IMSRA is compared quantitatively with IMD rain gauge and TMPA-3B42 daily data at a spatial scale of $0.25^{\circ}$ from June 1 to September 30, 2015 and different error statistics are calculated. There is no significant improvement in the correlation coefficient because only few points are corrected in a day due to the low temporal resolution of GMI compared to that of IN-
SAT-3D. However, there is a noticeable improvement in RMSD as seen in the time series plot in Figures 7 and 8 for IMD and TMPA-3B42, respectively; error statistics are given in Table III.

Further, the M-IMSRA data set is partitioned into orographic and non-orographic regions (heights greater than $500 \mathrm{~m}$ are categorized as orographic terrain) over the Indian territory (Fig. 9), and validation is performed separately for each region using IMD data. The scatter plot of IMSRA and M-IMSRA with IMD rainfall over orographic and non-orographic regions is given in Figure 10. The statistics over orographic regions show that the rain estimates from the IMSRA method have a poor correlation of 0.39 with a bias of $0.99 \mathrm{~mm}$ and a root mean square error of $20.53 \mathrm{~mm}$, whereas the M-IMSRA method has a correlation of 0.42 with a bias of $0.87 \mathrm{~mm}$ and a root mean square error of $19.36 \mathrm{~mm}$. Similarly, the statistics over non-orographic regions show that rain estimates from the IMSRA method have a correlation of 0.51 with a bias of $0.60 \mathrm{~mm}$ and a root mean square error of $17.08 \mathrm{~mm}$, whereas the M-IMSRA method has an improved correlation of 0.56 with a bias of $0.55 \mathrm{~mm}$ and a root mean square error of $15.12 \mathrm{~mm}$. The algorithm performs quite well over non-orographic regions, as is evident from the error statistics. However, the slightly poor performance of the algorithm over orographic regions is obviously (a) GPM-GMI rain $(\mathrm{mm} / \mathrm{h})$
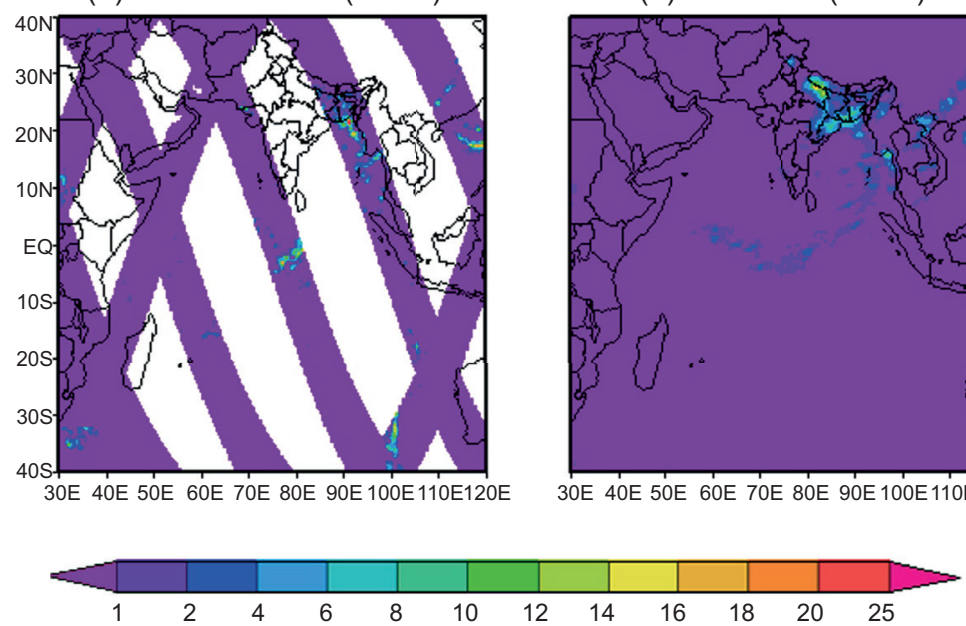

(c) Difference $(\mathrm{mm} / \mathrm{h})$
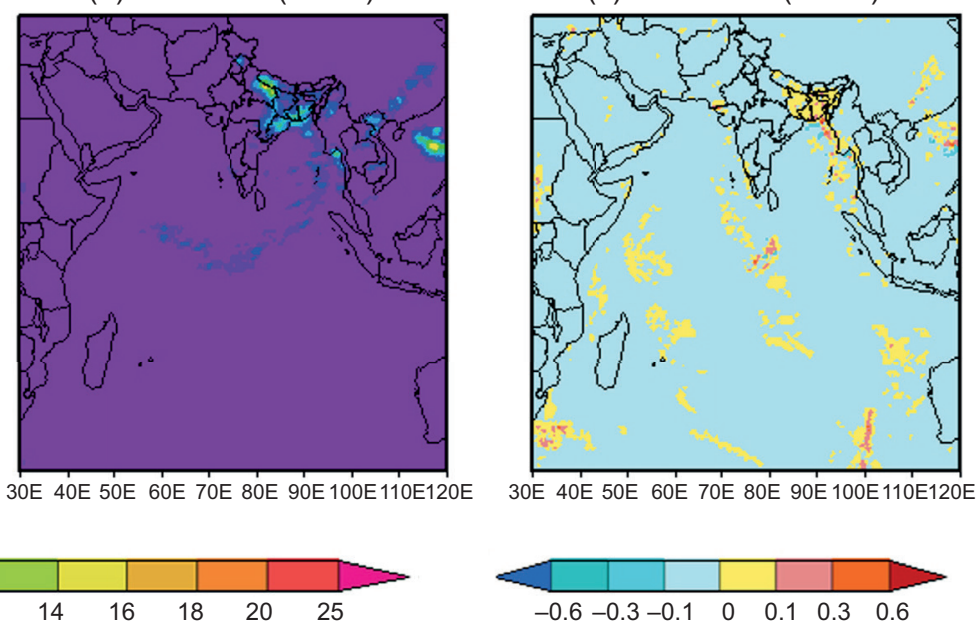

Fig. 6. (a) GPM-GMI average daily rainfall rate along its track on July 15, 2015. (b) IMSRA average daily rainfall rate on July 15, 2015 after successive correction. (c) Difference between M-IMSRA and IMSRA rainfall on July $15,2015$. 


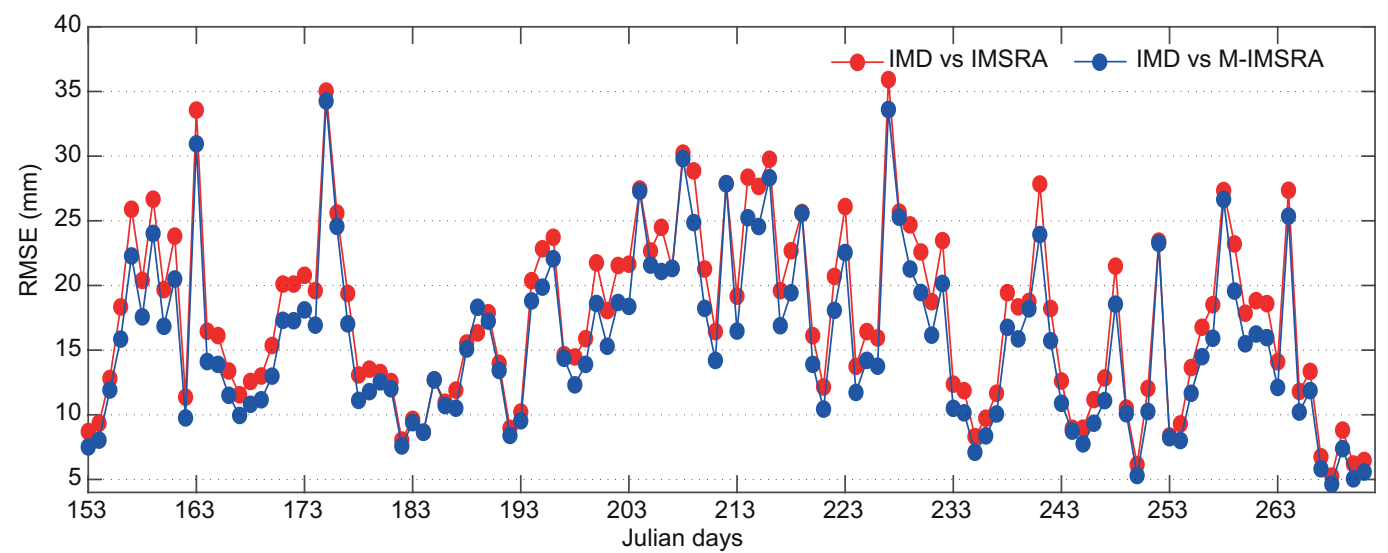

Fig. 7. Root mean square deviation of IMSRA and M-IMSRA with IMD rain at daily scale.

Table III. Statistics of M-IMSRA when compared to IMD gridded rainfall and TMPA-3B42 data for the period June 1 to September 30, 2015.

\begin{tabular}{lccccc}
\hline & \multicolumn{2}{c}{ Comparison with IMD rain } & & \multicolumn{2}{c}{ Comparison with TMPA-3B42 } \\
\cline { 2 - 3 } \cline { 5 - 6 } & IMSRA & M-IMSRA & & IMSRA & M-IMSRA \\
\hline Correlation coefficient (R) & 0.46 & 0.50 & & 0.63 & 0.68 \\
RMSD (mm) & 18.00 & 16.54 & & 9.31 & 7.42 \\
Bias (mm) & 0.76 & 0.60 & & -0.80 & -0.67 \\
Number of points & 588682 & 588682 & & 14124527 & 14124527 \\
\hline
\end{tabular}

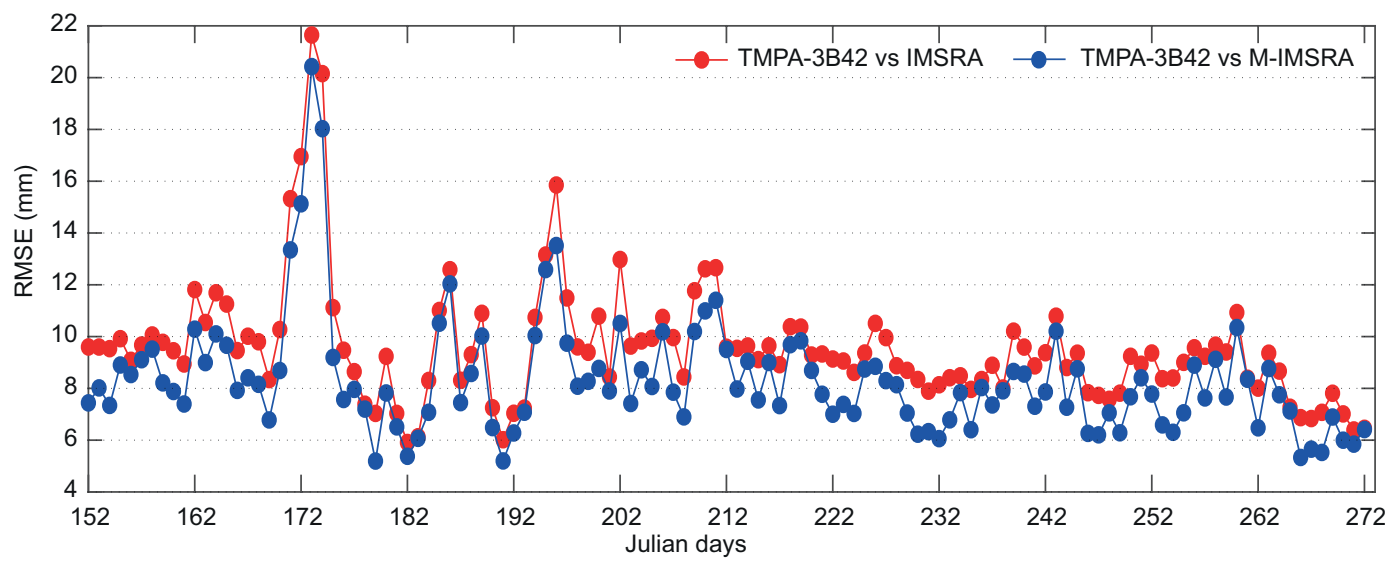

Fig. 8. Root mean square deviation of IMSRA and M-IMSRA with TMPA-3B42 at daily scale.

due to the land inhomogeneity and its influence on the distribution of precipitation.

The underestimation in the IR-based rainfall product can be rectified to a large extent if the MW-detected rainfall product is continuously present for that region. Thus, the missing patterns in IR-based products could also be included in the merged product in the presence of more reliable MW measurements. Until the development of new technology permits the portability of microwave sensors in geostationary orbits with similar temporal resolution as IR sensors, tropical rainfall could be monitored more reliably by having micro- 


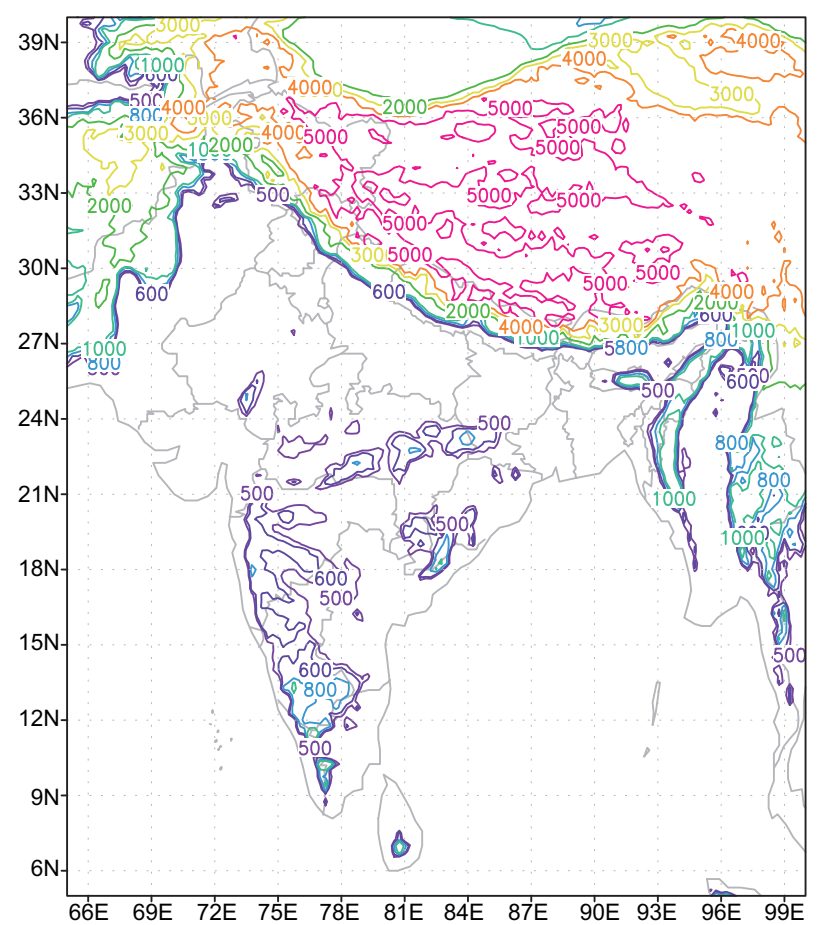

Fig. 9. Topography map of India showing orographic regions.
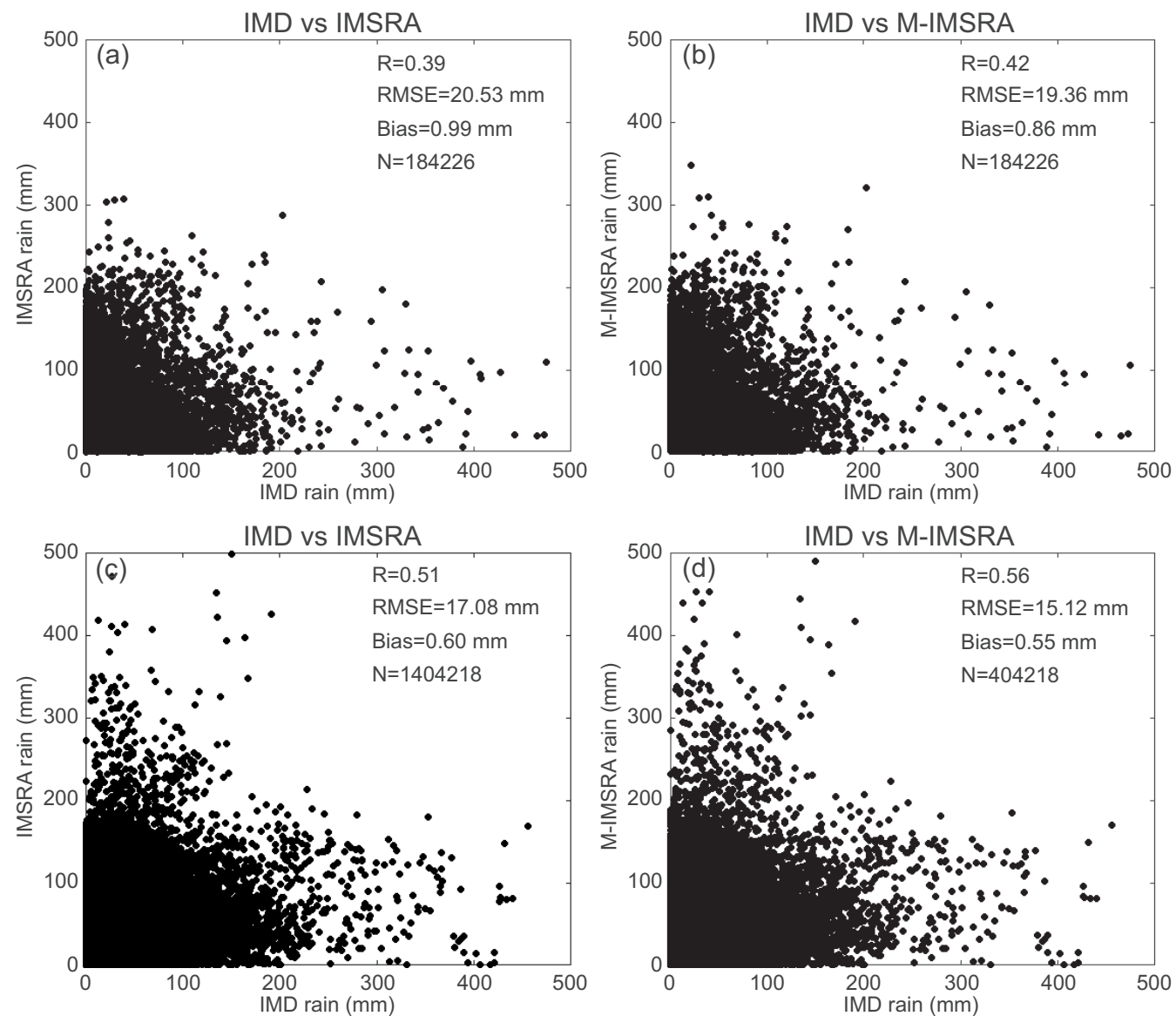

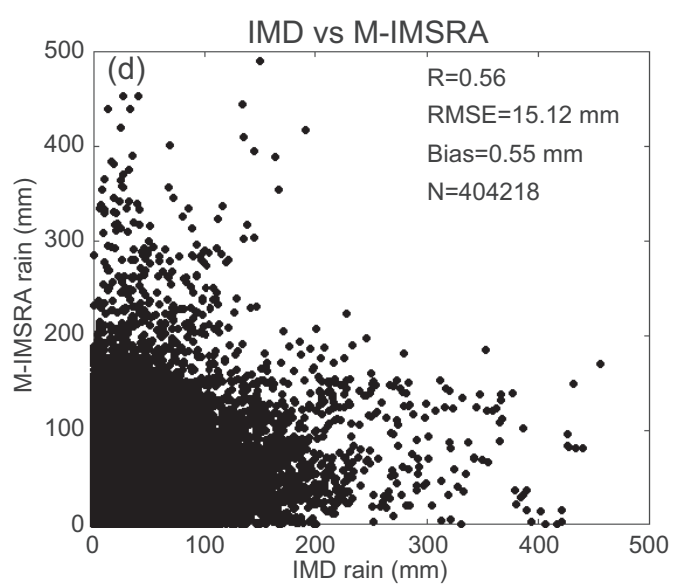

Fig. 10. Scatter plots between IMD rainfall and (a) IMSRA, (b) M-IMSRA over orographic regions, (c) IMSRA and (d) M-IMSRA over non-orographic regions for JJAS 2015. Bias, RMSD and correlation coefficient are given in each plot. 
wave sensors on low earth orbiting satellites such as TRMM $\left(35^{\circ}\right)$ and Megha-Tropiques (28 $)$. This study can be extended by optimally combining all possible microwave sensor observations with INSAT-3D for better products suited regionally to the Asian sector.

\section{Conclusions}

Near-real-time precipitation information at fine resolution is required to monitor flash floods. The combination of low earth orbiting microwave and geostationary IR-based measurements has a great potential for improving rainfall estimations on different temporal and spatial scales, and it can also address various other applications. This study is an attempt to estimate rainfall over the Indian monsoon region by the synergistic use of geostationary INSAT-3D TIR-derived IMSRA rainfall estimates and rain data from the GPM-GMI. The integrated IR and microwave method applied here for rainfall estimation shows a significant improvement over the IR-based rainfall estimates alone. This M-IMSRA product has been confirmed after the validation with IMD rain gauge data for a significant period of 122 days (June 1 to September 30, 2015) spanning the complete SW monsoon season. In addition, the comparison with independent satellite products such as TMPA-3B42, also confirms a considerable agreement in terms of root mean square deviation after correction. The qualitative and quantitative comparison shows that low inclination satellite microwave radiometer data can be used for further improvement of regional geostationary satellite data. It is concluded that M-IMSRA can provide regionally (in the Asian sector) precipitation information in a timely manner at fine spatial and temporal resolution required to monitor flash floods and daily monsoon performance. Furthermore, it is also recommended that polar orbiting GMI-like microwave sensors would be more suitable in low inclination satellite orbits like Megha-Tropiques and TRMM for significant coverage, in order to obtain more accurate tropical rainfall data for improving a number of application areas, including weather forecasting.

\section{Acknowledgements}

The authors would like to thank the Director of the Space Applications Centre, the Deputy Director,
EPSA, and the Group Director, AOSG for their support. We also thankfully acknowledge the following resources: INSAT-3D data was obtained from the website www.mosdac.gov.in, TMPA-3B42 rainfall data from the TRMM Online Visualization and Archive System (TOVAS), and the IMERG data from the Precipitation Processing System (PPS) (ftp:// arthurhou.pps.eosdis.nasa.gov/). We are also thankful to the anonymous reviewers for their helpful comments and suggestions.

\section{References}

Adler RF, Huffman GJ, Keehn PR. 1994. Global tropical rain estimates from microwave-adjusted geosynchronous IR data. Remote Sensing Reviews 11: 125-152. DOI: $10.1080 / 02757259409532262$

Arkin PA, Meisner BN. 1987. The relationship between large scale convective rainfall and cold cloud over the Western Hemisphere during 1982-84. Monthly Weather Review 115: 51-74.

DOI: $10.1175 / 1520-0493(1987) 115<0051$ :TR$\mathrm{BLSC}>2.0 . \mathrm{CO} ; 2$

Ashok Kumar, Maini Parvinder, Rathore LS, Singh SV. 2002. Skill of statistical interpretation forecasting system during monsoon season in India. Atmospheric Science Letters 3: 25-37. DOI: 10.1006/asle.2002.0055

Barrett EC, Martin DW. 1981. The use of satellite data in rainfall monitoring. Academic Press, 340 pp.

Brown PJ, Kummerow CD, Randel DL. 2016. Hurricane GPROF: An optimized ocean microwave rainfall retrieval for tropical cyclones. Journal of Atmospheric and Oceanic Technology 33: 539-1556.

DOI: 10.1175/JTECH-D-15-0234.1

Bushair MT, Satya Prakash, Shashikant Patel, Gairola RM. 2016. Assessment of Kalpana-1 rainfall product over Indian meteorological sub-divisions during the summer monsoon season. Journal of Indian Society of Remote Sensing 44: 67-76. DOI 10.1007/s12524-015-0465-1

Bushair MT, Prashant Kumar, Gairola RM. 2019. Evaluation and assimilation of various satellite-derived rainfall products over India. International Journal of Remote Sensing 40: 5315-5338.

DOI: 0.1080/01431161.2019.1579389

Cressman GP. 1959. An operative objective analysis system. Monthly Weather Review 87: 367-374.

DOI: $10.1175 / 1520-0493(1959) 087<0367$ :AOOAS $>$ 2.0.CO;2 
Ferraro RR, Grody NC, Marks GF. 1994. Effects of surface conditions on rain identification using the DMSP-SSM/I. Remote Sensing Reviews 11: 195-209. DOI: $10.1080 / 02757259409532265$

Gairola RM, Krishnamurti TN. 1992. Rain rates based on OLR, SSM/I and rain gauge data sets. Meteorology and Atmospheric Physics 50: 165-174.

DOI: $10.1007 / \mathrm{BF} 01026014$

Gairola RM, Varma AK, Agarwal VK. 2003. Rainfall estimation using spaceborne microwave radar and radiometric measurements. Mausam 54: 89-106.

Gairola RM, Mishra A, Prakash S, Mahesh C. 2010. Development of INSAT Multi-Spectral Rainfall Algorithm (IMSRA) for monitoring rainfall events over India using Kalpana-IR and TRMM-precipitation radar observations. Scientific report. SAC/EPSA/AOSG/ INSAT/SR-39/2010, 22 pp.

Gairola RM, Satya Prakash, Bushair MT, Pal PK. 2014. Rainfall estimation from Kalpana-1 satellite data over Indian land and oceanic regions. Current Science 107: 8-25.

Gairola RM, Satya Prakash Pal PK. 2015a. Improved rainfall estimation over the Indian monsoon region by synergistic use of Kalpana-1 and rain gauge data. Atmósfera 28: 51-61.

DOI: 10.20937/ATM.2015.28.01.05

Gairola RM, Varma AK, Mahesh C, Bushair M.T. 2015 b. Algorithm theoretical basis document. Rainfall estimation from IMSRA (modified). Scientific report. SAC/ EPSA/AOSG/SR/07/2015.

Hou AY, Kakar RK, Neeck S, Ardeshir, Azarbarzin, Kumerrow CD, Kojima M, Oki R, Naka-mura K, Iguchi T. 2014. The global precipitation measurement mission. Bulletin of the American Meteorological Society 95: 701-22. DOI: 10.1175/BAMS-D-13-00164-1

Huffman GJ, Adler RF, Stocker EF, Bolvin DT, Nelkin EJ. 2003. Analysis of TRMM 3-hourly multi-satellite precipitation estimates computed in both real and post-real time. 12th Conference on Satellite Meteorology and Oceanography 9-13 Feb, Long Beach, CA, 6 pp.

Huffman GJ, Bolvin DT, Nelkin E, Wolff DB. 2007. The TRMM Multisatellite Precipitation Analysis (TMPA): Quasi-global, multiyear, combined-sensor precipitation estimates at fine scales. Journal of Hydrometeorology 8: 38-55. DOI: 10.1175/JHM560.1

Huffman GJ, Bolvin DT, Braithwaite D, Hsu K, Joyce R, Kidd C, Nelkin EJ, Xie P. 2015. Algorithm theoretical basis document (ATBD) v. 4.5. Available at: http:// pmm.nasa.gov/sites/default/files/document_files/ IMERG_ATBD_V4.5.pdf (accessed on March 7, 2016).

Jangid BP, Prakash S, Bushair MT, Kumar R. 2017. Adding value to INSAT-3D sea surface temperature fields using MODIS data over the tropical Indian Ocean. Remote Sensing Letters 8: 458-467.

DOI: 10.1080/2150704X.2017.1280201

Joyce RJ, Xie P, Janowiak JE. 2011. Kalman filter-based CMORPH. Journal of Hydrometeorology 12: 15471563.

DOI: 10.1175/JHM-D-11-022.1

Kaila VK, Kiran Kumar AS, Sundarmurthy TK, Ramkrishnan S, Prasad MVS, Desai PS, Jayaraman V, Manikiam B. 2002. METSAT-A unique mission for weather and climate. Current Science 83: 1081-1088.

Kidder SQ, Vonder Haar TH. 1995. Satellite meteorology: An introduction. Academic Press, New York, 466 pp.

Kidd C, Kniveton DR, Todd MC, Bellerby TJ. 2003. Satellite rainfall estimation using combined passive microwave and infrared algorithms. Journal of Hydrometeorology 4: 1088-1104.

DOI: $10.1175 / 1525-7541(2003) 004<1088$ :SREUCP $>2.0 . \mathrm{CO} ; 2$

Kirschbaum D, Huffman G, Adler R, Braun S, Garrett K, Jones E, McNally A, Skofronick-Jackson G, Stocker E, Wu H, Zaitchik B. 2016. NASA's remotely-sensed precipitation: A reservoir for applications users. Bulletin of the American Meteorological Society.

DOI: 10.1175/BAMS-D-15-00296.1

Kubota T, Shige S, Hashizume H, Aonashi K, Takahashi N, Seto S, Takayabu YN, Ushio T, Nakagawa K, Iwanami K, Kachi M, Okamoto K. 2007. Global precipitation map using satellite borne microwave radiometers by the GSMaP project: Production and validation. IEEE Transactions on Geoscience and Remote Sensing 45: 2259-2275. DOI: 10.1109/TGRS.2007.895337

Kuligowski RJ. 2002. A self-calibrating real-time GOES rainfall algorithm for short-term rainfall estimates. Journal of Hydrometeorology 3: 112-130.

DOI: $10.1175 / 1525-7541(2002) 003<0112$ :ASCRT$\mathrm{G}>2.0 . \mathrm{CO} ; 2$

Kummerow C, Barnes W, Kozu T, Shiue J Simpson J. 1998. The Tropical Rainfall Measuring Mission (TRMM) sensor package. Journal of Atmospheric and Oceanic Technology 15: 809-817.

DOI: $10.1175 / 1520-0426(1998) 015<0809$ :TTRM$\mathrm{MT}>2.0 . \mathrm{CO} ; 2$ 
Kummerow C, Randel DL, Kulie M, Wang NY, Ferraro R, Munchak SJ, Petkovic V. 2015. The evolution of the Goddard profiling algorithm to a fully parametric scheme. Journal of Atmospheric and Oceanic Technology 32: 2265-2280.

DOI: 10.1175/JTECH-D-15-0039.1

Levizzani V, Amorati R, Meneguzzo F. 2002. A review of satellite-based rainfall estimation methods. Multiple-Sensor Precipitation Measurements, Integration, Calibration and Flood Forecasting. MUSIC-EVK1CT-2000-00058. Istituto di Scienze dell'Atmosfera e del Clima, Bologna, Italy.

Liu G, and Curry JA. 1993. Determination of characteristic features of cloud liquid water from satellite microwave measurements. Journal of Geophysical Research 98: 5069-5092. DOI: 10.1029/92JD02888

Mahesh C, Prakash S, Sathiyamoorthy V, Gairola RM. 2011. Artificial neural network-based microwave precipitation estimation using scattering index and polarization corrected temperature. Atmospheric Research 102: 358-364. DOI: 10.1016/j.atmosres.2011.09.003

Mahesh C, Prakash S, Sathiyamoorthy V, Gairola RM. 2014a. An improved approach for rainfall estimation over Indian summer monsoon region using Kalpana-1 data. Advances in Space Research 54: 565-808.

DOI: 10.1016/j.asr.2014.04.019

Mahesh C, Prakash S, Gairola RM, Shivani S, Pal PK. 2014b. Meteorological sub-divisional scale rainfall monitoring using kalpana-1 VHRR measurements. Geographical Research 52: 328-336.

DOI: $10.1111 / 1745-5871.12068$

Mason IB. 2003. Binary events in forecast verification. A practitioner's guide in atmospheric science (Jolliffe I, Stephenson D, Eds.). Wiley, United Kingdom, 37-76.

Mitra AK, Dasgupta M, Singh SV, Krishnamurti TN. 2003. Daily rainfall for Indian monsoon region from merged satellite and rain gauge values: Large-scale analysis from real-time data. Journal of Hydrometeorology 4:769-781.

DOI: $10.1175 / 1525-7541(2003) 004<0769$ : DRFTIM $>2.0 . \mathrm{CO} ; 2$

Mitra AK, Bohra AK, Rajeevan MN, Krishnamurti TN. 2009. Daily Indian precipitation analyses formed from a merge of rain-gauge with TRMM TMPA satellite derived rainfall estimates. Journal of the Meteorological Society of Japan 87: 265-279.

DOI: $10.2151 / \mathrm{jmsj} .87 \mathrm{~A} .265$
Mitra AK., Momin IM, Rajagopal EN, Basu S, Rajeevan MN Krishnamurti TN. 2013. Gridded daily Indian monsoon rainfall for 14 seasons: Merged TRMM and IMD gauge analyzed values. Journal of Earth System Science 122: 1173-1182.

DOI: $10.1007 / \mathrm{s} 12040-013-0338-3$

Pai DS, Sridhar L, Rajeevan M, Sreejith OP, Satbhai NS, Mukhopadhyay B. 2014. Development of a new high spatial resolution $\left(0.25^{\circ} \times 0.25^{\circ}\right)$ long period (19012010) daily gridded rainfall data set over India and its comparison with existing data sets over the region. Mausam 65: 1-18.

Prakash S, Mahesh C, Mishra A, Gairola RM, Varma AK, Pal PK. 2009. Combined use of microwave and IR data for the study of Indian monsoon rainfall-2009. ISPRS Archives XXXVIII-8/W3-Impact of Climate Change on Agriculture, December 17-18, Ahmedabad, India, 227-230.

Prakash S, Mahesh C, Gairola RM, Pal PK. 2010. Estimation of Indian summer monsoon rainfall using Kalpana-1 VHRR data and its validation using rain gauge and GPCP data. Meteorology and Atmospheric Physics 110: 45-57. DOI: 10.1007/s00703-010-0106-8

Prakash S, Mitra AK, Pai DS, Agha Kouchak A. 2015. From TRMM to GPM: How well can heavy rainfall be detected from space? Advances in Water Resources 81: 1-7. DOI: 10.1016/j.advwatres.2015.11.008

Roca R, Viollier M, Picon L, Desbois M., 2002. A multisatellite analysis of deep convection and its moist environment over the Indian Ocean during the winter monsoon. Journal of Geophysical Research 107: 1-25. DOI: $10.1029 / 2000 J D 000040$

Selvaraju R. 2003. Impact of El Niño-Southern Oscillation on Indian food grain production. International Journal of Climatology 23: 187-206. DOI: 10.1002/joc.869

Sorooshian S, Hsu KL, Gao X, Gupta HV, Imam B, Braithwaite D. 2000. Evaluation of PERSIANN system satellite-based estimates of tropical rainfall. Bulletin of the American Meteorological Society 81: 2035-2046. DOI: $10.1175 / 1520-0477(2000) 081<2035$ :EOPSSE $>2.3 . \mathrm{CO} ; 2$

Spencer RW, Goodman HM, Hood RE. 1989. Precipitation retrieval over land and ocean with the SSM/I: Identification and characteristics of the scattering signal. Journal of Atmospheric and Oceanic Technology 6: 254-273.

DOI: $10.1175 / 1520-0426(1989) 006<0254$ :PRO$\mathrm{LAO}>2.0 . \mathrm{CO} ; 2$ 
Stephenson DB, Casati B, Ferro CAT, Wilson CA. 2008. The extreme dependency score: A non-vanishing measure for forecasts of rare events. Meteorological Applications 15: 41-50. DOI: $10.1002 /$ met.53

Thiebaux HJ, Pedder MA. 1987. Spatial Objective analysis - with applications in atmospheric science. Academic Press, London, 299 pp.

Turk FJ, Miller SD. 2005. Toward improved characterization of remotely sensed precipitation Regimes with MODIS/AMSR-E blended data techniques. IEEE Transactions on Geoscience and Remote Sensing 43: 1059-1069.

DOI: 10.1109/TGRS.2004.841627
Wilheit T, Adler R, Avery S, Barrett E, Bauer P, Berg W, Chang A, Ferriday J, Grody N, Goodman S, Kidd C, Kniveton D, Kummerow C, Mugnai A, Olson W, Petty G, Shibata A, Smith E. 1994. Algorithms for the retrieval of rainfall from passive microwave measurements. Remote Sensing Reviews 11: 163-194.

DOI: $10.1080 / 02757259409532264$

Wilks DS. 1995. Statistical Methods in Atmospheric Sciences.Academic Press: New York, NY.

Xu L, Gao X, Sorooshian S, Arkin PA, Imam B. 1999. A microwave infrared threshold technique to improve the GOES precipitation index. Journal of Applied Meteorology 38: 569-579. DOI: 10.1175/ 1520-0450(1999)038<0569:amittt>2.0.co;2 